\title{
The Rise and Fall of Uncitedness
}

\section{Charles A. Schwartz}

Large-scale uncitedness refers to the remarkable proportion of articles that do not receive a single citation within five years of publication. Equally remarkable is the brief and troubled history of this area of inquiry, which was prone to miscalculation, misinterpretation, and politicization. This article reassesses large-scale uncitedness as both a general phenomenon in the scholarly communication system and a case study of library and information science, where its rate is 72 percent.

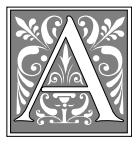

unique episode in the field of scholarly communication began with a December 1990 report in Science of an unsuspected phenomenon: 55 percent of scientific articles do not receive a single citation within five years of publication. ${ }^{1}$ A few weeks later, another report in $\mathrm{Sci}$ ence by the same research body, the Institute for Scientific Information (ISI), noted still higher rates of uncitedness for the social sciences $(75 \%)$ and humanities $(92 \%) .^{2}$ Those reports attracted a lot of attention, even in the popular press.

In a March 1991 letter to the editors of Science, ISI said that because of the "great interest in the numbers" on uncitedness already released, it now would produce a new study which would be based on a more meaningful approach and would show rates of uncitedness separately for subdivisions in the sciences, social sciences, and humanities. ${ }^{3}$ However, no such study ever appeared.

Among the new findings eventually produced, but not published, was the rate of uncitedness in library and information science (LIS). This rate turned out to be 72 percent. $^{4}$

This article reassesses large-scale uncitedness on a couple of levels: as a general phenomenon in the scholarly communication system, and as a case study of LIS. Its main themes can be set forth briefly. First, large-scale uncitedness indicates that there are significantly fewer patterns of influence or interaction in the scholarly communication system than had been assumed previously. Second, uncitedness statistics covering entire disciplines are too amorphous to be related to any specific group of researchers in a particular subdiscipline (field or specialization). Journal co-citation network analysis, which focuses on specific patterns of citedness and uncitedness at subdisciplinary levels, provides a more coherent framework of inquiry. Third, uncitedness rates are less informative than measures of the extreme variance of citedness among articles within the same journal. Finally, for a practitioner literature such as LIS, there is a clear issue of uncitedness versus usefulness. 


\begin{tabular}{|lccc|}
\hline \multicolumn{4}{|c|}{ TABLE 1 } \\
\multicolumn{4}{|c|}{ Uncitedness by Level of Data Disaggregation } \\
\hline \hline $\begin{array}{l}\text { Level of Disaggregation } \\
\text { of Citation Databases }\end{array}$ & $\begin{array}{l}\text { Physical } \\
\text { Sciences }\end{array}$ & $\begin{array}{l}\text { Social } \\
\text { Sciences }\end{array}$ & Humanities \\
\hline $\begin{array}{l}\text { Level 1: No disaggregation } \\
\text { (all source items included) }\end{array}$ & $47 \%$ & $75 \%$ & $98 \%$ \\
$\begin{array}{l}\text { Level 2: Articles only } \\
\text { (marginalia eliminated) }\end{array}$ & $22 \%$ & $48 \%$ & $93 \%$ \\
$\begin{array}{l}\text { Level 3: U.S. authors only } \\
\text { Ratios for articles-only } \\
\text { adjustments }\end{array}$ & $14 \%$ & - & - \\
\hline $\begin{array}{l}\text { Sources: Level 1: Hamilton, note 1; Level 2: Hamilton, note 2; Level 3: } \\
\text { Pendlebury, note 3. }\end{array}$ & & & \\
\hline
\end{tabular}

variation stems from the methodological problem of disaggregation. In order to handle this problem, ISI's databasesgeared to measurement of citedness would have to be restructured into different units of analysis in the difficult effort to gauge the opposite phenomenon of uncitedness.

The 55 and 47 percent uncitedness fig-

Beyond this introductory sketch, this article is developed in four parts. Part one examines the problem of disaggregation in the measurement of uncitedness. Part two reviews the reactions of the popular press and scholars in the early 1990s to large-scale uncitedness. Part three is a case study of uncitedness in College $\mathcal{E}$ Research Libraries (CERL), which occupies the central-most position in the LIS journal co-citation network. And part four provides a brief summary and suggests some areas for future research.

The maxim that "it's important to know what's in the numbers before interpreting them" is crucial to analysis of uncitedness.

\section{The Problem of Disaggregation}

The maxim that "it's important to know what's in the numbers before interpreting them" is crucial to analysis of uncitedness. Consider the extraordinary range of ISI's various estimates for uncitedness in the physical sciences as a group: 55 percent, 47 percent, 22 percent, and then 14 percent. All these statistics have some basis, yet even the 14 percent figure (covering only citation of fulllength articles written by U.S. authors) is too inflated to be meaningful. Such ures were both drawn from the entire ISI physical science database. However, this database includes not only articles but also "marginalia" (e.g., book reviews, conference abstracts, editorials, letters, and obituaries), which are seldom cited. Limiting the database to articles only (i.e., eliminating marginalia) cuts uncitedness to 22 percent. ${ }^{5}$ Then, limiting the database to U.S. authors cuts it one third more (14\%). Nevertheless, general statistics for the physical science disciplines as a whole would require further disaggregation because they were skewed by extraordinary counterexamples, such as the 72 percent rate of uncitedness in engineering.

Disaggregation might seem a takenfor-granted analytical need but, initially, ISI had overlooked even marginalia. As table 1 shows, the rates of uncitedness dropped sharply in the physical sciences and social sciences, though only slightly in the humanities, once the correct unit of analysis-articles only-was recognized in ISI's March 1991 letter to Science.

Table 2 shows partly disaggregated estimates of uncitedness rates for some disciplines. The different adjustment (reduction) ratios - for the sciences (0.47), the social sciences (0.64), and the humanities (0.95) - were extrapolated from table 1 . In a procedure that is indicative rather than 


\begin{tabular}{|c|c|c|}
\hline \multicolumn{3}{|c|}{$\begin{array}{c}\text { TABLE } 2 \\
\text { Uncitedness Rates } \\
\end{array}$} \\
\hline Discipline & $\begin{array}{c}\text { No } \\
\text { Disaggregation } \\
\end{array}$ & $\begin{array}{l}\text { Articles } \\
\text { Only* }\end{array}$ \\
\hline \multicolumn{3}{|c|}{ Physical Sciences } \\
\hline $\begin{array}{l}\text { Average } \\
\text { Examples }\end{array}$ & \multicolumn{2}{|c|}{ Examples } \\
\hline$\overline{\text { Physics }}$ & 37 & 17 \\
\hline Biological Sciences & 41 & 19 \\
\hline Geosciences & 44 & 21 \\
\hline Medicine & 46 & 22 \\
\hline Mathematics & 55 & 26 \\
\hline Engineering & 72 & 34 \\
\hline \multicolumn{3}{|l|}{ Social Sciences } \\
\hline \multicolumn{3}{|l|}{ Examples } \\
\hline$\overline{\text { Archaeology }}$ & 76 & 49 \\
\hline Business & 77 & 49 \\
\hline Sociology & 77 & 49 \\
\hline Anthropology & 80 & 51 \\
\hline Linguistics & 80 & 51 \\
\hline Intern'l. Relations & 83 & 53 \\
\hline Political Science & 90 & 58 \\
\hline Library Science & - & 72 \\
\hline \multicolumn{3}{|l|}{ Humanities } \\
\hline \multicolumn{3}{|l|}{ Examples } \\
\hline Philosophy & 92 & 88 \\
\hline History & 95 & 91 \\
\hline Religious Studies & 98 & 93 \\
\hline Architecture & 99 & 95 \\
\hline American Literature & 99 & 95 \\
\hline Theater & 99 & 95 \\
\hline \multicolumn{3}{|c|}{$\begin{array}{l}\text { * The figures in this column were derived in two } \\
\text { steps. First, each "average" in this column, taken } \\
\text { from table 1, was derived by ISI by eliminating } \\
\text { marginalia from its database for that broad group. } \\
\text { Second, the adjustment ratio for each of the three } \\
\text { groups (also shown in table } 1 \text { ) was multiplied by } \\
\text { the figures in the first column cited as "examples" } \\
\text { of component disciplines. }\end{array}$} \\
\hline
\end{tabular}

precise, the adjustment ratio for each of these three broad groups was applied in table 2 as an across-the-board correction for the component disciplines selected as examples.
Table 2 demonstrates what ISI acknowledged in its March 1991 letterthat the problem of disaggregation "serves to illustrate the great range of statistics one can derive depending upon what 'cut' is made from the databases." ${ }^{6}$ Can the adjusted figures in table 2 be taken at face value? No, they would require further disaggregation. As noted above, ISI estimated that restricting the data to U.S. authors would cut only the uncitedness rate for articles in the physical sciences by a third. In the social sciences, the impact of this disaggregation factor would be smaller inasmuch as national boundaries in the scholarly system are stronger in those disciplines. For example, one study showed that only 8 percent of articles published in journals of the American Sociological Association, the American Psychological Association, and the American Political Science Association have foreign authors. ${ }^{7}$

More important, disaggregation would have to deal with the breakup of the disciplines in the wake of the increasing specialization of research since the 1960s. The social sciences and humanities are widely known to have become conglomerations of rather distinct fields with fairly autonomous journal networks. Subdisciplinary statistics are necessary to adjust uncitedness to more revealing levels. Thus, although the uncitedness rate is 95 percent for history and 92 percent for philosophy, the small interdisciplinary field of the history and philosophy of science has only a 29 percent rate. The physical sciences are not very different in this respect. For example, chemistry's overall uncitedness rate- 28 percent (adjusted for marginalia)-covers extreme variations, from 17 percent uncitedness in nuclear fields to 78 percent in applied fields. ${ }^{8}$ The essential point is that the disciplinewide, international statistics on uncitedness in table 2 are too broad to be meaningful. 


\section{Reactions to Large-Scale Uncitedness}

Disaggregating a discipline into subdisciplines is complicated, involving scores or even hundreds of journal co-citation network analyses. Although ISI has enough computer power and expertise to undertake that, the fact that it did not release a single such report indicates that

\section{One thesis suggests that intellectual progress depends on a long line of minor discoveries being made by a host of average scholars working on relatively unambitious projects.}

other considerations were involved-one of those doubtless being the realization that large-scale uncitedness was not simply a matter of "great interest" but also constituted a controversial and troublesome area.

ISI's reports on uncitedness for broad disciplines carried the implicit issue, which editorials about those reports made explicit, of whether uncited literature has any real worth. The popular press treated this issue with cavalier remarks, such as one attributed to a professor: "If the bottom 80 percent of the literature just vanished, I doubt if the scientific enterprise would suffer." ${ }^{9}$ Newsweek interpreted ISI's reports to mean that "nearly half the scientific work in this country is basically worthless." It went on to call for more rigorous standards in federal funding programs and wound up describing "scientists, with their belief in their God-given right to taxpayer dollars, [as] welfare queens in white coats." 10

Some scholarly responses to ISI's reports put a polite veneer on the issue of uncitedness by alluding to certain historical perspectives. ${ }^{11}$ One such perspective was the Ortega thesis (of the 1930s), which suggests that intellectual progress depends on a long line of minor discoveries being made by a host of average scholars working on relatively unambitious projects. ${ }^{12}$ In that view, uncited literature is not necessarily insignificant. Alternatively, the Cole thesis (of the 1970s) holds that only a few scholars contribute to intellectual progress and that even relatively small discoveries come principally from the upper strata of the scholarly system. ${ }^{13}$

Scholars who focused more directly on ISI's reports drew three very different interpretations of large-scale uncitedness. One was to denounce citation practices; another was to blame ISI's methodology; and the third was to find no reason to blame or worry, attributing large-scale uncitedness simply to normal statistical probabilities.

\section{Citation Practices}

Too many researchers, it was said, do not bother with literature searches or care to credit other authors:

Thus the gauntlet should be thrown down, not upon the hundreds of papers never cited, but upon those who refuse to acknowledge or cite them, deliberately or not, who refuse to admit that out there are possible gems if only they would take the time to dig them out. The political upshot is that some research projects, being unknowingly redundant of previously published works, are a "waste of time, effort, and [funding agencies'] money." 14

A difficulty with this interpretation is that poor research practices do not necessarily "add up" to large-scale uncitedness in a discipline. On the contrary, citation counts over the long term probably err on the side of overinclusion rather than exclusion, at least for significant or interesting source items. Although researcher $A$ may fail to cite the important work of researcher $B$, it is unlikely that everyone else in that field will 
make the same omission over the course of five years. ${ }^{15}$

\section{ISI's Methodology}

A few scholars reacted to ISI's findings by conducting their own case studies as "reality checks." Against ISI's initial 55 percent uncitedness rate for the physical sciences, one study found a 5 percent rate for astronomy and an 8 percent rate for physics. ${ }^{16}$ And against ISI's initial 75 percent uncitedness rate for the social sciences, another study found a 9 percent rate for sociology. ${ }^{17}$

In the main, these enormous differences were attributed to ISI's failure to eliminate marginalia from its databases. However, as table 1 shows, fixing that preliminary methodological problem would not have brought ISI's findings in line with those case studies. Rather, the fundamental factor was that each study was based on a small set of prestigious journals. In astronomy, four journals were analyzed as opposed to ISI's set of thirty-two for that discipline; in physics, only four of ISI's 196 journals were analyzed; and in sociology, twenty-one of ISI's seventy-three journals.

Not surprisingly, all those select journals have a high-impact factor (the ratio between annual citations and annual citable items). Yet, what is interesting is that all the case studies found a low correlation between a journal's impact factor and an article's citedness. For example, in sociology, "73 percent of the variance in article citations was within journals; thus, there is roughly three times as much variation within journals as between them." 18 Therefore, estimating the longterm significance of an article by the perceived quality or impact factor of the journal in which it appears is simplistic:

Assigning the same value to all articles in a journal will overestimate the less influential and underestimate the more influential articles, thus effectively leveling out the very differences that [citation] evaluation procedures should seek to identify. ${ }^{19}$

In general, basing a citation study on a small set of prestigious journals will reduce uncitedness substantially. Although based on such an unrepresentative sample, that kind of analysis has more "cognitive utility" to researchers than one based on scores of unfamiliar journals spread over an entire discipline.

\section{Normal Statistical Probabilities}

Per Seglen, a Norwegian chemist, has shown that certain kinds of scholarly or athletic achievements have parallel probabilities in the upper range of a normal statistical distribution. These include writing a highly cited article, being a highly productive researcher, and running a marathon in the top 20 percent of the field. High citedness, in particular, correlates with an inverse power function, called Lotka's law, first developed to measure research productivity. It states that the number of scientists producing $n$ papers is approximately the reciprocal of n-squared (i.e., proportional to $1 / \mathrm{n}^{2}$ ).

\section{Yet, what is interesting is that all the case studies found a low correlation between a journal's impact factor and an article's citedness.}

Seglen's interpretation of the opposite phenomenon of large-scale uncitedness combined statistical assumptions and journal space limitations with the traditional optimism of the Ortega thesis:

The fact that a large fraction of the scientific literature is uncited does not mean that it is not being read, or that it does not contribute to scientific progress; it means that the total number of citations [allowed 
by journal editors with an eye to space limitations] is simply too small to give room for all [significant or interesting] articles. As part of a continuous probability distribution, each uncited paper has a definite probability of being influential. If nothing else, it is safe to assume that all publications exert some influence upon their authors, an influence which may become manifest in other, more heavily cited articles. ${ }^{20}$

That is probably the best case one could make for ISI's findings. Yet, it is doubtful that it would prevail in the event that large-scale uncitedness became a politicized issue for federal funding programs.

A difficulty with Seglen's view is that it lumped together low citedness and complete uncitedness as the same residual effect of Lotka's law. It is one thing

\section{But large-scale uncitedness across} the scholarly system was striking.

to argue that low citedness is a normal statistical probability, but quite another to conclude that a large part of a literature going completely uncited - and thus without any perceptible impact on the scholarly communication system - is an inevitable phenomenon. In that regard, if ISI had merely reported that low citedness was common, that would have been a dull or routine finding. But largescale uncitedness across the scholarly system was striking.

\section{Uncitedness in Library and Information Science}

The 72 percent uncitedness rate for LIS was based on the following parameters: of 4,139 articles published within ISI's set of 53 LIS journals in 1984, 2,970 (seven of every ten) had not received a single citation after five years.

\section{Citation Practices}

As we have seen, some scholars reacted to the discovery of large-scale uncitedness by denouncing poor citation practices. Although there are two studies that bear on such practices in LIS in 1984 (the baseline of ISI's investigation), it is not possible to relate them to the 72 percent uncitedness rate. The problem lies in the noncomparability of the two studies, which have disproportionate sample sets of data.

The first study found that 76 percent of the LIS literature in 1984 did not include any citations, presumably because three out of four articles were how-to or opinion pieces. ${ }^{21}$ The second study, however, showed nearly the opposite: only 18 percent of the literature did not include citations; moreover, the other four-fifths of the literature was heavily referenced (with fourteen citations per average article). ${ }^{22}$ The noncomparability of those findings lies in the different scale and caliber of the sample sets. The first study was comprehensive $(2,869$ articles spread over ninety LIS journals), whereas the second was based on a much more select sample set (328 articles in fifty journals indexed in ERIC).

\section{The Case of C\&RL}

As we also have seen, other scholars reacted to large-scale uncitedness by conducting their own case studies as "reality checks." Such studies were inevitably based on a small or even tiny set of wellknown journals, because the scholars lacked the computer power of ISI and, in addition, were naturally inclined to stick to familiar ground. For our purposes - to assess the 72 percent rate for LIS in a context that is familiar or relevant to the readership of this article-it may suffice to begin by considering uncitedness in CERL.

The case of $C \mathcal{E} R L$ provides some support for those who would argue that citation practices have surely improved since 1984. Over the past decade, 
$C \mathcal{E} R L$ 's impact factor nearly doubled (from 0.655 to 1.160). ${ }^{23}$ Even during the period of ISI's investigation (1984 to 1989), the percentage of this journal's articles having no references decreased, and the average number of citations per article nearly doubled (from fourteen to twenty-four). ${ }^{24}$

For a contemporary perspective, a citation analysis of the forty-six articles of volume 50 (1989) was done (by the author) for the five-year period 1990 through 1994. The uncitedness factor for CERL turned out to be 26 percent. Although that is the reverse of ISI's rate for LIS as a whole, the mean number of citations to the forty-six articles was only 1.16 (CERL's impact factor for 1989). More important, this analysis revealed what similar kinds of case studies in other disciplines had discovered in the early 1990s: the extreme variance of citedness among articles within the same journal. In a nutshell, 26 percent ( $\mathrm{n}=12$ articles) were not cited, 52 percent $(n=24)$ were cited only once, 18 percent $(n=8)$ were cited three or four times, and 4 percent $(n=2)$ were cited eleven or twelve times. ${ }^{25}$ Such variance is masked by a relatively simple impact factor or its opposite number, an uncitedness rate.

To get a broader picture of the workings of uncitedness in our discipline, journal co-citation network analysis is useful. The analysis presented below draws on a model originally developed by Ronald E. Rice in a different context (citation ties between LIS and communication studies). ${ }^{26}$

\section{Journal Network Analysis}

In LIS, as in any discipline, researchers use and generate different subdisciplinary bodies of literature in which distinct interests are addressed. Each subdisciplinary body encompasses a network of journals whose respective $X$-axis positions (on a line of loosely coupled subdisciplines) and Y-axis positions (in a hierarchy of citation ranks) are mapped according to certain input/output properties. Two journals (or occasionally literatures) are interactive to the extent that articles in one cite articles in another. Interactiveness may be hierarchical, with a more influential journal serving as a "feeder" to another journal, which would be a "storer." Or, interactiveness may be congruent, with journals citing each other in proportion to the number of times they are themselves cited by those journals. ${ }^{27}$

Conversely, journals or literatures may be relatively or absolutely noninteractive, having few or no citations in common. Noninteractiveness reflects systemic patterns of uncitedness (journals $x$ and $y$ being mutually isolated) or broader latitudes of disciplinary fragmentation (subdisciplinary literatures $A$ and $B$ being mutually isolated).

In LIS, the journal co-citation network map comprises three largely autonomous subdisciplines. CERL is the leader of library science, which focuses on researchoriented studies of practice and policy and on applications of new information technologies. Other high-status journals in this network include $R Q$ and Library Trends, each of which has a congruent (proportional) co-citation relation to $C \mathcal{E R L}$; the Journal of Academic Libraries $(J A L)$, which is a storer of CERL; and $L i$ brary Resources and Technical Services, a storer of $C \mathcal{E} R L$ but a feeder to other technical services journals farther down the hierarchy, such as Library Acquisitions and Government Publications Review.

The Journal of the American Society for Information Science (JASIS) is the leader of the second subdiscipline, information science, which focuses on information retrieval, theoretical aspects of information technologies, and bibliometrics. Other high-status journals in this network include Library Quarterly, the Journal of Information Science, the Journal of Documentation, and Online Review. Farther down the hierarchy are three storers of JASIS: Information Processing and Management, Electronic Library, and the $\mathrm{Ca}$ - 
nadian Journal of Information Science. In a sub-subdiscipline are three storers of Library Quarterly: American Archivist, International Library Review, and Aslib Proceedings.

Library Journal is the leader of the third subdiscipline, librarianship, which focuses on nonacademic libraries, practitioner reports, and professional news. Other high-status journals in this network include the Bulletin of the Medical Library Association, Online, Special Libraries, and Law Library Journal. Farther down the hierarchy are Serials Librarian; Canadian Library Journal; the Journal of Library History, Philosophy, and Comparative Librarianship; Information Technology and Libraries; and Database.

There are remarkably few citation patterns between the three subdisciplines; those that exist are occasional (not regular) and flow to or from library sciencei.e., there are no salient communication channels between librarianship and information science. Library science and librarianship have three occasional and unidirectional linkages: $C \mathcal{E} R L, J A L$, and $R Q$ all cite Library Journal from time to time, but it does not cite them. Library science and information science once had a "bridge" pattern, a low-level congruency, between CERL and JASIS in the mid-1980s, but those leaders now are mutually noninteractive. Library Quarterly alone is a link to library science as a storer of CERL and feeder to Library Resources and Technical Services.

Library Quarterly has a unique history of having been in all three subdisciplines. During the 1970s, it had a congruent cocitation pattern with Library Journal in librarianship. In the early 1980s, it had moved to library science, positioned first between $J A L$ (as a storer) and $R Q$ (as a feeder), and later just below $C \mathcal{E} R L$ in status. Since the late-1980s, it has been part of information science. ${ }^{28}$

\section{Concluding Observations}

The publication of ISI numbers showing high rates of uncitedness for major disciplines in the sciences, social sciences, and humanities attracted widespread attention and reaction. However, it also led to a problem. Although measurement of uncitedness at the majordiscipline level was technically feasible, it generated findings that had only limited meaning, were misinterpreted, and would be challenged by anyone's "reality check" of a few select journals. At the same time, the promised new work on uncitedness at the subdiscipline level was by no means certain to prove technically feasible or to generate more palatable results.

Although disaggregating marginalia and foreign authors was easy for ISI to do, rescaling its databases to calculate scores (or hundreds) of subdisciplinary uncitedness rates would have been a huge engineering task. As other research shows, it would have been highly subjective as well. To conceptualize and delineate what are variously termed research specialties, fields, communities, invisible colleges, networks, etc., is a severely ambiguous problem. ${ }^{29}$ Further, ISI's decision not to embark on the promised new project may well have included an understandable concern that politicization of large-scale uncitedness might have an adverse effect on federal funding programs, impairing its relations with the rest of the scholarly community.

Nevertheless, large-scale uncitedness was an important discovery signifying a far more loosely coupled, noninteractive scholarly communication system than anyone had suggested. ${ }^{30}$ LIS, for example, has only two salient patterns of influence or interaction between subdisciplines; both are unidirectional and establish CERL's central-most position in the LIS system, as a storer of Library Journal messages (from librarianship) and as a feeder of messages to Library Quarterly (in information science). There is no twoway (congruent) co-citation pattern between any of the subdisciplines; they are 
largely autonomous. (Perhaps the lack of any pattern linking information science and librarianship reflects the proverbial gap between theory and practice.)

Although such general patterns of noninteractiveness are useful for visualizing uncitedness, they do not "prove" or "disprove" ISI's findings. At any rate, uncitedness is an elusive concept and rates of uncitedness have a widely differing significance or meaning among units of the scholarly communication system. Also noteworthy, uncitedness is less informative than the extreme variance of citedness among articles within the same journal. Comparative analysis in this area might prove interesting. Is the variance within $C \mathcal{E} R L$ (ranging for volume 50 from one-quarter of articles being uncited after five years, to half being cited once and a fifth being cited a few times, to a twentieth being heavily cited) a stable or erratic phenomenon? Is that similar to the variance within other LIS journals? Would citation analysis of a whole set of heavily cited articles yield reliable generalizations about such significant influence or interaction in our profession's research literature?

On a final note, one other unexplored area warrants future research. It involves the issue of uncitedness versus usefulness for practitioner-oriented articles or journals. We know, for example, that $C \mathcal{E} R L$ News (which is not even included in ISI's database) is more "valued" than $C \mathcal{E} R L$ by the membership of the Association of College and Research Libraries. ${ }^{31}$ Also, at least a few electronic articles have been retrieved many thou-

\section{Uncitedness is less informative than the extreme variance of citedness among articles within the same journal.}

sands of times, although articles in electronic journals generally have a negligible impact in the scholarly communication system, as measured by citation analysis. ${ }^{32-33}$ Of course, retrieval (downloading or printing) is no more a measure of usefulness than citation is a signifier of scholarly quality. Nevertheless, research in this area might enable us to put in better perspective the phenomenon of large-scale uncitedness, as well as the image of LIS as a fragmented discipline with discrete journal networks operating in small, bounded subdisciplines. ${ }^{34}$

\section{Notes}

1. David P. Hamilton, "Publishing by-and for? - the Numbers," Science 250 (Dec. 7, 1990): 1331-32. Large-scale uncitedness had been unsuspected because the few earlier studies, based on small samples of medical literature, found rates below 10 percent. See Derek de Solla Price, "Networks of Scientific Papers," Science 149 (July 30, 1965): 512; and Richard E. Stern, "Uncitedness in the Biomedical Literature," Journal of the American Society for Information Science 41 (Apr. 1990): 193-96.

2. - - - "Research Papers: Who's Uncited Now," Science 251 (Jan. 4, 1991): 25.

3. "We will be generating, over the coming months, article-only statistics, both U.S. and worldwide, for subdisciplines in the sciences, social sciences, and humanities, corresponding to the overall database statistics referred to by Hamilton in his second article. We have not yet produced a report on these statistics but, in light of the great interest in the numbers, we will now do so." David Pendlebury, "Letter," Science 251 (Mar. 22, 1991): 1410-11. See also, Eugene Garfield, "To Be an Uncited Scientist Is No Cause for Shame," in Essays of an Information Scientist 14, ed. Eugene Garfield (Philadelphia: ISI Pr., 1991), 390-91.

4. Personal communication with David Pendlebury, ISI, Dec. 8, 1994. The specific uncitedness figures are provided in the section on uncitedness in LIS.

5. There are counterexamples to many generalizations about uncitedness. On the importance of one type of marginalia, letters to journal editors, in one field, see Bluma C. Peritz, "The Citation Impact of Letters to the Editor: The Case of Lancet," Scientometrics 20 (1991): 121-29. 
6. Pendlebury, "Letter."

7. William Gareau, "The Increasing Ethnocentrism of American Social Science," International Journal of Comparative Sociology 24 (Sept.-Dec. 1983): 248; see also, E. Ernst and T. Kienbacher, "Chauvinism," Nature 352 (Aug. 15, 1991): 560.

8. Pendlebury, "Letter."

9. Sharon Begley, "Gridlock in the Labs," Newsweek 125 (Jan. 14, 1991): 44-45.

10. Ibid.

11. "Science, Citation, and Funding," Letters, Science 251 (Mar. 22, 1991): 1408-11; Samuel C. Patterson, "The Impact of the American Political Science Review," PS: Political Science and Politics (Dec. 1991): 765-74; Garfield, "To Be an Uncited Scientist;" "The Uncitedness Index," Editorial, Surgical Neurology 37 (1992): 69-70; "Fashion and the Great Uncited," Editorial, New Scientist 131 (May 15, 1993): 3.

12. J. Ortega y Gasset, The Revolt of the Masses (New York: Norton, 1932), 84-85; cited in Per O. Seglen, "The Skewness of Science," Journal of the American Society for Information Science 43 (1992): 628-38.

13. Jonathan R. Cole and Stephen Cole, "The Ortega Hypothesis," Science 178 (Oct. 27, 1972): 368-75; cited in Lowell L. Hargens, "Impressions and Misimpressions about Sociology Journals," Contemporary Sociology 20 (May 1991):343-49.

14. Philip Siekevitz, "Citations and the Tenor of the Times," Editorial, Faseb Journal 5 (Jan. 1991): 139-40.

15. Although what we "ought" to cite is still a subjective matter, a set of investigations has found that citations are often decorations, ritual obeisances, or otherwise perfunctionary in nature. See Terrence A. Brooks, "Private Acts and Public Objects: An Investigation of Citer Motivations," Journal of the American Society for Information Science 36 (July 1985): 223-29; and Eugene Garfield, "Citation Behavior-An Aid or a Hindrance to Information Retrieval," in Essays of an Information Scientist 12, ed. Eugene Garfield (Philadelphia: ISI Pr., 1989), 123-28.

16. Helmut A. Abt, "Letter," Science 251 (Mar. 22, 1991): 1408-9.

17. David M. Bott and Lowell L. Hargens, "Are Sociologists' Publications Uncited? Citation Rates of Journal Articles, Chapters, and Books," American Sociologist 22 (summer 1991): 147-58.

18. Ibid., 153.

19. Seglen, "The Skewness of Science," 631.

20. Ibid., 635.

21. Patrica E. Feehan et al, "Library and Information Science Research: An Analysis of the 1984 Journal Literature," Library and Information Science Research 9 (1987): 173-85.

22. John M. Budd, "The Literature of Academic Libraries: An Analysis," College \& Research Libraries 52 (May 1991): 290-95.

23. SSCI Journal Citation Reports (Philadelphia: ISI, various years).

24. Paul Metz, "A Statistical Profile of College \& Research Libraries," College \& Research Libraries 50 (Jan. 1989): 42-47.

25. The coauthors of those highly cited articles in volume 50 of $C \mathcal{E} R L$ were Charles R. McClure and Ann Bishop; Stephen E. Wiberley Jr. and William G. Jones.

26. Ronald E. Rice, "Hierarchies and Clusters among Communication and Library and Information Science Journals, 1977-1987," in Scholarly Communications and Bibliometrics, ed. Christine L. Borgman (Newbury Park, Calif.: Sage, 1990), 138-53.

27. Journal co-citation network patterns are drawn mainly from the SSCI Journal Citation Report for 1994. On input/output properties, see Mary T. Kim, "A Comparison of Three Measures of Journal Status: Influence Weight, Importance Weight, and Measure of Standing," Library and Information Science Research 14 (1992): 75-96; Gerald R. Salancik, "An Index of Subgroup Influence in Dependency Networks," Administrative Science Quarterly 31 (1986): 194-211; Robert V. Eagly, “Economics Journals As a Communications Network," Journal of Economic Literature 13 (Sept. 1975): 878-88.

28. When Library Quarterly shifted from library science to information science, Canadian Law Journal went in the opposite direction. Previously a storer of Library Quarterly when the latter was in library science, it became a storer of the Bulletin of the Medical Library Association in the librarianship subdiscipline.

29. On the general ambiguity of conceptualizing subdisciplines, see D. E. Chubin, "Beyond Invisible Colleges: A Bibliographic Essay," in Sociology of Sciences: An Annotated Bibliography, ed. D. E. Chubin (New York: Garland, 1983), 3-63.

30. On the concept of loose coupling, see Charles A. Schwartz, "Scholarly Communication As a Loosely Coupled System: Reassessing Prospects for Structural Reform," College \& Research Libraries 55 (Mar. 1994): 101-17. 
31. Althea H. Jenkins, "Members Shape ACRL's Future," College \& Research Libraries News 55 (June 1994): 368-72.

32. In a citation analysis of 4,317 references in 279 scholarly, peer-reviewed articles appearing in 74 electronic journals, only $83(1.9 \%)$ were to online sources; and only nine $(0.2 \%)$ were to electronic journals. More than 80 percent of those references were concentrated in just three electronic journals: Public Access Computer Systems Review (PACS-R), Electronic Journal on Virtual Culture, and Ejournal. Stephen P. Harter, "The Impact of Electronic Journals on Scholarly Communication: A Citation Analysis," Public-Access Computer Systems Review 7, no. 5 (1966). PACS Review is available at http://info.lib.uh.edu/pacsrev.html.

33. The following PACS-R articles had the top retrieval rates for 1995; numbers of retrievals are for 1995 only (they are not cumulative counts that would include retrievals in prior years). A complete cumulative count would include, for example, in the case of Caplan's paper (below), an additional 2,058 retrievals for 1994. Retrievals: Priscilla Caplan, "Cataloging Internet Resources," 1993 (9,218); Charles W. Bailey Jr., "Network-Based Electronic Publishing of Scholarly Works: A Selective Bibliography," 1995 (6,649); Jeff Barry, "The Hypertext Markup Language (HTML) and the World Wide Web: Raising ASCII Text to a New Level of Usability," 1994 (2,002); Peter Scott, “Using HYTELNET to Access Internet Resources," 1992 (1,738); Roderick D. Atkinson and Laurie E. Stackpole, "TORPEDO: Networked Access to Full-Text and Page-Image Representations of Physics Journals and Technical Reports," $1995(1,558)$.

For full-citation and hypertext access to these (and all other) PACS-R articles: http:// info.lib.uh.edu/pacsrev/html. Retrieval counts are from a personal communication with PACS-R editor Charles W. Bailey Jr., June 14, 1996.

34. Consider, for example, a similarity between engineering and LIS in Burkart Holzner, Knowledge Application (Boston: Allyn \& Bacon, 1979), 226: “In a comparison between seven engineering projects and two scientific projects in physics, it was found that 51 percent of the ideas in the scientific research came from the formal scientific literature. However, only 8 percent of ideas in the engineering projects came from this source. On the other hand, in the engineering projects, respondents reported that 33 percent of the ideas came from vendors of potential equipment or subsystems or from the customers of the products being developed. These sources did not play any role in the research projects." 